\title{
Formas de ferro e alumínio e suas relações com textura, mineralogia e carbono orgânico em Latossolos do Cerrado
}

\section{Iron and aluminum forms and their relationship with texture, mineralogy and organic carbon in the Cerrado Oxisol}

\author{
Pedro Rodolfo Siqueira Vendrame ${ }^{1 *}$; Diogo Néia Eberhardt'; Osmar Rodrigues \\ Brito $^{3}$; Robélio Leandro Marchão ${ }^{4}$; Cécile Quantin ${ }^{5}$; Thierry Becquer ${ }^{6}$
}

\begin{abstract}
Resumo
Os Latossolos da região do Cerrado apresentam mineralogia da fração argila relativamente simples, sendo constituídos principalmente por caulinita e óxidos de ferro e de alumínio. O objetivo deste trabalho foi realizar extrações sequênciais de ferro e de alumínio e relacioná-los à mineralogia, textura e teores de carbono orgânico em Latossolos da região do Cerrado. Coletaram-se 35 amostras na camada de 0-20 $\mathrm{cm}$ de Latossolos sob pastagem da região do Cerrado. Os teores de ferro e de alumínio extraídos pelo ataque total, ditionito-citrato-bicarbonato de sódio, oxalato ácido de amônia e pirofosfato de sódio foram analisados de acordo com a classe textural através do teste não paramétrico de Kruskal-Wallis. Em seguida estes dados foram relacionados com a mineralogia e o carbono orgânico por meio de uma análise de componentes principais. Independentemente da classe textural, os óxidos de ferro de alto grau de cristalinidade representaram a principal forma de ferro e se correlacionam positivamente com os teores totais de ferro. Os óxidos de alumínio apresentaram maior afinidade ao carbono orgânico do que os óxidos de ferro. Os teores de ferro e alumínio extraídos pelo pirofosfato foram estreitamente relacionados ao $\mathrm{pH}$ dos solos.
\end{abstract}

Palavras-chave: Extrações sequênciais, óxidos de ferro e alumínio, cristalinidade, Latossolos

\begin{abstract}
The Oxisols of the Cerrado region have a simple mineralogy, and are composed mainly of kaolinite and iron and aluminium oxides. The aim of this work was to perform a sequential extraction of iron and aluminium and to relate them to texture, mineralogy and organic carbon in Oxisols of the Cerrado region. The soil samples, 35 in total, were taken from the $0-20 \mathrm{~cm}$ layer in Oxisols under pasture located in the Brazilian Cerrado Region. The levels of iron and aluminum extracted by full attack, dithionite-citrate-bicarbonate, ammonium oxalate and sodium pyrophosphate were analyzed according to the textural classes using the Kruskal-Wallis nonparametric test. Then these data were related to the mineralogy and organic carbon through a principal component analysis. Whatever the textures, iron oxides of high degree of crystallinity were the main form of iron and are positively correlated with the iron total content. The aluminum oxides have a high affinity to organic carbon than iron oxides. The
\end{abstract}

\footnotetext{
1 Prof. do Dept ${ }^{\circ}$ de Geociências, Universidade Estadual de Londrina, UEL. Rodovia Celso Garcia Cid, PR 445, Km 380, C P 6001, CEP 86051-990, Londrina, PR. E-mail: vendrame@uel.br

2 Doutorando do Programa de Pós-Graduação em Solos e Nutrição de Plantas, Escola Superior de Agricultura Luiz de Queiroz, ESALQ/USP, Piracicaba, SP. E-mail: diogone@yahoo.com.br

3 Prof. do Dept ${ }^{0}$ de Agronomia, UEL, Londrina, PR. E-mail: osmar@uel.br

4 Pesquisador da Embrapa Cerrados, Planaltina, DF. E-mail: robelio.leandro@cpac.embrapa.br

5 Prof ${ }^{\text {a }}$ do Département de Science de la Terre, Université Paris-Sud 11, Orsay, França. E-mail: quantin@geol.u-psud.fr

${ }^{6}$ Pesquisador do Institut de Recherche pour le Développement, UMR 210 Eco\&Sols, Montpellier, França. E-mail: thierry. becquer@ird.fr
}

* Autor para correspondência 
levels of iron and aluminum extracted by sodium pyrophosphate were closely related to soil $\mathrm{pH}$.

Key words: Sequential extractions, iron and aluminium oxides, crystallinity, Oxisols

\section{Introdução}

Os Latossolos da região do Cerrado apresentam mineralogia da fração argila relativamente simples, sendo constituídos principalmente por caulinita e por óxidos e hidróxidos de Fe e de Al. Alguns Latossolos, formados de rochas básicas e ricas em $\mathrm{Fe}$, apresentam também, na fração argila, a maghemita (GOMES et al., 2004) e, na fração areia, a magnetita e a ilmenita (KÄMPF; SCHEINOST; SCHULZE, 2000).

Os óxidos de $\mathrm{Fe}$ apresentam considerável influência nas propriedades físicas e químicas dos solos devido aos seus variados graus de cristalinidade e por apresentarem cargas variáveis dependentes do $\mathrm{pH}$ do solo. Nos Latossolos estão presentes principalmente nas formas de goethita e hematita. Esta última, com acentuado poder de pigmentação, é determinante da coloração de muitos solos (GENÚ; DEMATTÊ; FIORIO, 2010). A formação da hematita é favorecida pela ocorrência de altas temperaturas, enquanto que a goethita é formada em condições de baixo $\mathrm{pH}$, alta umidade e altas concentrações de carbono (GHIDIN et al., 2006).

Os óxidos de Al estão representados nos Latossolos principalmente pela gibbsita, e sua presença está relacionada ao intemperismo intenso, favorecido pelas altas temperaturas e circulação intensa de água, permitindo a saída de sílica e bases do sistema (GHIDIN et al., 2006). Dependendo do valor do $\mathrm{pH}$ do solo, os óxidos de Al participam diretamente da retenção de ânions e cátions, sendo um dos minerais que mais adsorve o P (EBERHARDT et al., 2008). Além disso, os óxidos de $\mathrm{Al}$ exercem maior influencia nos atributos físico-químicos do solo do que os óxidos de $\mathrm{Fe}$ (PEDROTTI et al., 2003). Diversos pesquisadores têm realizado o $\left.46^{\circ} 48^{\prime} 36^{\prime \prime} \mathrm{W}\right)$. fracionamento das formas de $\mathrm{Fe}$ e $\mathrm{Al}$ presentes nos solos (COSTA et al., 2002; INDA JUNIOR; KAMPF, 2003; OLIVEIRA; NASCIMENTO, 2006; VENDRAME et al., 2007). A avaliação é realizada basicamente sob três formas: $\mathrm{Fe}$ e $\mathrm{Al}$ totais, $\mathrm{Fe}$ e $\mathrm{Al}$ constituintes dos óxidos pedogênicos e Fe e $\mathrm{Al}$ constituintes dos óxidos pedogênicos de baixa cristalinidade (INDA JUNIOR; KAMPF, 2003). Os óxidos de $\mathrm{Fe}$ e $\mathrm{Al}$ pedogênicos são comumente extraídos pelo método do ditionitocitrato-bicarbonato de sódio (DCB). $\mathrm{O} F e$ e o $\mathrm{Al}$ constituintes dos óxidos pedogênicos de baixa cristalinidade são extraídos pelo oxalato de amônia (reativo de Tamm) e o Fe e o Al complexados pelo húmus do solo são extraídos pelo pirofosfato de sódio alcalino (KÄMPF; SCHEINOST; SCHULZE, 2000). Embora esses autores tenham descrito as formas de $\mathrm{Fe}$ e $\mathrm{Al}$ presente em várias classes de solos, pouco se conhece das relações entre essas formas e os atributos dos solos como a mineralogia e o conteúdo de carbono orgânico.

Desta forma, este trabalho foi conduzido com o objetivo de avaliar as relações entre as diferentes formas de ocorrência do ferro e alumínio e a textura, mineralogia e conteúdo de carbono orgânico de Latossolos da região do Cerrado.

\section{Material e Métodos}

Os solos estudados, 35 no total, foram coletados nos anos de 2004 e 2005, em três regiões: às margens das rodovias GO-060 e BR-154, entre os municípios de Goiânia, GO, e Barra do Garças, MT (15'34'40"S a $16^{\circ} 39^{\prime} 34^{\prime \prime}$ S e $49^{\circ} 20^{\prime} 48^{\prime \prime} \mathrm{W}$ a

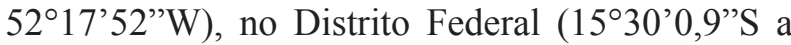
$16^{\circ} 1^{\prime} 11^{\prime \prime}$ S e $47^{\circ} 22^{\prime} 0,9^{\prime \prime} \mathrm{W}$ a $48^{\circ} 11^{\prime} 58^{\prime \prime} \mathrm{W}$ ), e nos municípios de Unaí e Paracatu, noroeste de Minas

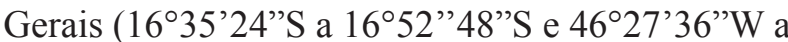


Para a definição e localização dos pontos de amostragem, foram consultados mapas geológicos e pedológicos, tendo sido selecionados apenas locais compostos pela classe dos Latossolos. As amostras foram coletadas apenas em relevos planos ou suavemente ondulados. Todas as áreas selecionadas estavam ocupadas por pastagens e os pontos de amostragem foram georreferenciados com auxílio de equipamento GPS.

Em cada ponto de amostragem, foram coletadas amostras da camada superficial do solo $(0-20 \mathrm{~cm})$, com auxílio de trado tipo holandês construído com material inoxidável. Foram realizadas três tradagens (distanciadas de 1,0 m), a fim de se obter maior quantidade e homogeneidade das amostras.

As análises químicas e texturais foram realizadas de acordo com as metodologias descritas por Claessen (1997). Foram determinados: pH em água (relação 1:2,5); $\mathrm{K}$ disponível, extraído com a solução Mehlich-1 $\left(0,0125 \mathrm{~mol} \mathrm{~L}^{-1} \mathrm{de}_{2} \mathrm{SO}_{4}\right.$ e 0,050 mol L-1 de $\mathrm{HCl}$ ); $\mathrm{Al}, \mathrm{Ca}$ e $\mathrm{Mg}$ trocáveis, extraídos com $\mathrm{KCl} 1 \mathrm{~mol} \mathrm{~L}{ }^{-1} ; \mathrm{H}+\mathrm{Al}$, extraídos com solução de acetato de cálcio $0,5 \mathrm{~mol} \mathrm{~L}^{-1}$ a pH 7 e titulados com $\mathrm{NaOH} 0,0606 \mathrm{~mol} \mathrm{~L}^{-1}$. Com os resultados obtidos foram calculados: a soma de bases (SB), a capacidade de troca cationica a $\mathrm{pH} 7(\mathrm{CTCpH}$ 7) e a saturação por bases (V). Para avaliação do carbono orgânico (C-org), empregou-se o método da oxidação por dicromato de potássio e titulação com sulfato ferroso (método Walkley \& Black). Os teores disponíveis de Fe foram determinados em espectrofotômetro de absorção atômica, após a extração com DTPA (LINDSAY; NORVELL, 1978).

No "Département de Science de la Terre da Université Paris-XI", França, foram realizadas as seguintes determinações: $\mathrm{Fe}_{2} \mathrm{O}_{3}$ e $\mathrm{Al}_{2} \mathrm{O}_{3}$ através de ataque total com $\mathrm{HF}+\mathrm{HClO}_{4}+\mathrm{HCl}+\mathrm{HNO}_{3}$ (SUN; CHI; SHIUE, 2001); $\mathrm{Fe}_{\mathrm{d}}$ e $\mathrm{Al}_{\mathrm{d}}$ através de extração com DCB (ditionito-citrato-bicarbonato de sódio (MEHRA; JACKSON, 1960)); $\mathrm{Fe}_{\mathrm{o}}$ e $\mathrm{Al}_{\mathrm{o}}$ com o extrator Tamm (oxalato ácido de amônia) e $\mathrm{Fe}_{\mathrm{p}}$ e $\mathrm{Al}_{\mathrm{p}}$ com Pirofosfato de sódio (adaptado de WANG, 1978). A leitura dos extratos foi realizada em equipamento de espectrocospia de emissão atômica ICP-AES (inductively coupled plasma atomic emission spectroscopy). As quantidades de caulinita $(\mathrm{Ct})$ e gibbsita $(\mathrm{Gb})$ foram determinadas através de análise termogravimétrica (ATG), com aparelho TGA-50 Shimadzu no laboratório de Solos da Embrapa Cerrados (MELO et al., 2001).

Todos os dados obtidos foram submetidos a análises estatísticas descritivas, para obtenção das médias e amplitudes de variação. Para as variáveis oriundas do ataque total, DCB, Tamm e Pyrofosfato, realizaram-se análises estatísticas de acordo com a classe textural dos solos mediante aplicação do teste não paramétrico de Kruskal-Wallis. Quando a estatística H de Kruskal-Wallis indicou diferenças significativas, utilizou-se o teste de Dunn para comparar as médias dos postos, por ser um teste mais conservador ao retificar o nível alfa conforme o número de amostras, que neste caso foi diferente para cada classe textural. Nesta etapa utilizou-se o programa BioEstat 5.0 (AYRES et al., 2007).

Empregou-se ainda a análise de componentes principais (ACP) mediante uso do programa ADE4 (THIOULOUSE et al., 1997), com o intuito de agrupar, comparar e relacionar as diferentes formas de $\mathrm{Fe}$ e $\mathrm{Al}$ com a mineralogia, textura e teores de $\mathrm{C}$ orgânico dos solos. A ACP reduz as dimensões dos dados e, de acordo com Gomes et al. (2004), é uma ferramenta adequada para comparação e entendimento das diferenças e similaridades em ambientes pedológicos diversos.

\section{Resultados e Discussão}

Os resultados de média, mínimo, máximo e desvio-padrão das variáveis relativas às análises químicas, mineralógica e texturais estão apresentados na Tabela 1. 
Tabela 1. Valores médios, mínimos, máximos e desvio-padrão (DP) para variáveis associadas às análises texturais, químicas e mineralógicas de Latossolos da região do Cerrado.

\begin{tabular}{|c|c|c|c|c|}
\hline Variável & Média & Mínimo & Máximo & $\mathbf{D P}$ \\
\hline Argila $\left(\mathrm{g} \mathrm{kg}^{-1}\right)$ & 438,52 & 150,00 & 720,00 & 150,26 \\
\hline Silte $\left(\mathrm{g} \mathrm{kg}^{-1}\right)$ & 97,41 & 0,00 & 310,00 & 74,33 \\
\hline Areia fina $\left(\mathrm{g} \mathrm{kg}^{-1}\right)$ & 323,15 & 50,00 & 710,00 & 121,08 \\
\hline Areia grossa $\left(\mathrm{g} \mathrm{kg}^{-1}\right)$ & 140,93 & 10,00 & 440,00 & 126,85 \\
\hline $\mathrm{C}\left(\mathrm{g} \mathrm{kg}^{-1}\right)$ & 16,0 & 7,6 & 32,1 & 5,2 \\
\hline $\mathrm{pH}_{\mathrm{H} 2 \mathrm{O}}$ & 5,77 & 4,89 & 8,30 & 0,63 \\
\hline $\mathrm{H}+\mathrm{Al}\left(\mathrm{cmol}_{\mathrm{c}} \mathrm{kg}^{-1}\right)$ & 4,62 & 0,12 & 9,02 & 1,68 \\
\hline $\mathrm{Al}^{+3}\left(\mathrm{cmol}_{\mathrm{c}} \mathrm{kg}^{-1}\right)$ & 0,41 & 0,00 & 1,51 & 0,41 \\
\hline $\mathrm{Ca}^{2+}\left(\mathrm{cmol}_{\mathrm{c}} \mathrm{kg}^{-1}\right)$ & 1,41 & 0,00 & 4,55 & 1,15 \\
\hline $\mathrm{Mg}^{2+}\left(\mathrm{cmol}_{\mathrm{c}} \mathrm{kg}^{-1}\right)$ & 0,75 & 0,16 & 1,70 & 0,43 \\
\hline $\mathrm{K}^{+}\left(\mathrm{cmol}_{\mathrm{c}} \mathrm{kg}^{-1}\right)$ & 0,14 & 0,03 & 0,72 & 0,13 \\
\hline CTC $\left(\mathrm{cmol}_{\mathrm{c}} \mathrm{kg}^{-1}\right)$ & 6,92 & 3,44 & 11,00 & 1,66 \\
\hline $\mathrm{SB}\left(\mathrm{cmol}_{\mathrm{c}} \mathrm{kg}^{-1}\right)$ & 2,30 & 0,55 & 5,14 & 1,41 \\
\hline$V(\%)$ & 33,03 & 8,33 & 97,71 & 18,77 \\
\hline $\mathrm{Gb}\left(\mathrm{g} \mathrm{kg}^{-1}\right)$ & 164,32 & 9,50 & 414,70 & 106,90 \\
\hline $\mathrm{Ct}\left(\mathrm{g} \mathrm{kg}^{-1}\right)$ & 320,99 & 106,50 & 613,00 & 125,71 \\
\hline
\end{tabular}

Fonte: Elaboração dos autores.

Os teores de carbono variaram de 7,6 a $32,1 \mathrm{~g} \mathrm{~kg}^{-1}$, com média em $1,60 \mathrm{~g} \mathrm{~kg}^{-1}$. Estes valores são parecidos com aqueles apresentados por Marques et al. (2004) $\left(\mathrm{C}=17,0 \mathrm{~g} \mathrm{~kg}^{-1}\right)$ para solos sob vegetação nativa do Cerrado, mas ficaram abaixo daqueles apresentados por Lilienfein et al. (2003) (C = 22,0 $\left.\mathrm{g} \mathrm{kg}^{-1}\right)$ para solos sob pastagens degradas da região do triangulo mineiro.

Os teores de argila dos solos utilizados neste estudo variaram de 150 a $720 \mathrm{~g} \mathrm{~kg}^{-1}$, portanto, de acordo com Santos et al. (2006), a classificação textural variou de média até muito argilosa. Com relação à mineralogia, as análises termogravimétricas revelaram teores médios de caulinita de $321 \mathrm{~g} \mathrm{~kg}^{-1} \mathrm{e}$ de gibbsita de $164 \mathrm{~g}$ $\mathrm{kg}^{-1}$, com teores de caulinita superiores aos de gibbsita em $90 \%$ dos solos, o que está de acordo os resultados obtidos por Gomes et al. (2004) que sugeriram cautela na generalização acerca da riqueza em gibbsita dos Latossolos da Região do Cerrado.

Os resultados de média, mínimo, máximo, desviopadrão e dos testes de significância das variáveis oriundas do ataque total, DCB, oxalato ácido de amônia e pirofosfato de sódio estão apresentados na Tabela 2.

Os teores médios de $\mathrm{Fe}_{2} \mathrm{O}_{3}$ foram de 40,7, 111,9 e $109,3 \mathrm{~g} \mathrm{~kg}^{-1}$, com amplitudes entre 13,1 - 119,8; 58,5 - 247,8 e 57,8 - 180,2 $\mathrm{g} \mathrm{kg}^{-1}$ para os solos com textura média, argilosa e muito argilosa, respectivamente, o que permite classifica-los desde hipo a perférricos (SANTOS et al., 2006). Os teores médios de $\mathrm{Al}_{2} \mathrm{O}_{3}$ foram de 103,9, 262,2 e 287,5 $\mathrm{g} \mathrm{kg}^{-1}$, com amplitudes entre 41,4 e 215,3; 118,0 e 410,3; 217,8 e $371,5 \mathrm{~g} \mathrm{~kg}^{-1}$ para os solos com textura média, argilosa e muito argilosa, respectivamente. Em geral os teores totais de $\mathrm{Al}_{2} \mathrm{O}_{3}$ foram 2,5 vezes superiores ao de $\mathrm{Fe}_{2} \mathrm{O}_{3}$, o que está de acordo com os dados de Reatto et al. (2008) que avaliaram Latossolos nas duas principais superfícies geomórficas da região do Cerrado (Velhas e Sul Americana).

As menores quantidades de $\mathrm{Fe}_{2} \mathrm{O}_{3}$ e $\mathrm{Al}_{2} \mathrm{O}_{3}$ foram verificadas nos solos com texturas médias, o que está de acordo com o esperado. Por outro lado, 
entre as classes argilosa e muito argilosa não foram verificadas diferenças significativas no conteúdo destes compostos. As amplitudes observadas para os valores destes constituintes, dentro das mesmas classes texturais, podem ser explicadas pela grande extensão da área de amostragem, onde há influências de diferentes materiais de origem e condições de drenagem.

Os teores de $\mathrm{Al}_{\mathrm{p}}$ e $\mathrm{Fe}_{\mathrm{p}}$ (extração com pirofosfato de sódio) não variaram em função da classificação textural. Este resultado pode ser explicado pelo fato de o pirofosfato extrair preferencialmente os óxidos de $\mathrm{Fe}$ e de $\mathrm{Al}$ ligados à matéria orgânica e, portanto, seus teores variam principalmente em função da quantidade deste material nos solos (PARFITT; CHILDS, 1988). De maneira geral, os valores médios de $\mathrm{Al}_{\mathrm{p}}$ são maiores que os de $\mathrm{Fe}_{\mathrm{p}}$, demonstrando maior afinidade dos óxidos de alumínio com a matéria orgânica, quando comparado aos óxidos de ferro, o que está de acordo com Arias, Barral e Diaz-Fierros (1996). Essa maior afinidade dos óxidos de Al com a matéria orgânica se deve, principalmente, a maior superfície específica deste mineral, pois, a matéria orgânica apresenta uma grande concentração de grupos funcionais, dentre os quais se destacam os grupos carboxílicos que apresentam capacidade de estabelecer interações via reações de coordenação com os grupos $-\mathrm{OH}$, presentes na superfície destes minerais (CORNEJO; HERMOSÍN, 1996).

Verificaram-se maiores teores de $\mathrm{Al}_{\mathrm{o}}$ e Fe (extração $_{\mathrm{o}}$ com oxalato acido de amonia) e $\mathrm{Al}_{d}$ e $\mathrm{Fe}_{\mathrm{d}}$ (extração DCB) nos solos de textura argilosa e muito argilosa, seguindo a mesma tendência observada para os teores totais destes elementos (Tabela 2). Estes resultados se devem ao fato de os óxidos de Fe e de Al extraídos por DCB e Tamm representarem os óxidos de alta e baixa cristalinidade, respectivamente, estando relacionados à fração argila dos solos (Tabela 2).

Os valores de $\mathrm{Al}_{\mathrm{d}}$ representam, em sua maior parte, o alumínio contido na estrutura dos óxidos de Fe e pode-se inferir que os maiores valores de $\mathrm{Al}_{d}$ correspondem à maior ocorrência de substituições isomórficas de Fe por $\mathrm{Al}$ nas estruturas dos óxidos de ferro.

Os teores de $\mathrm{Fe}_{\mathrm{o}}$ são extremamente baixos se comparados aos de $\mathrm{Fe}_{\mathrm{d}}$, o que pode ser confirmado pela baixa razão $\mathrm{Fe}_{\mathrm{o}} / \mathrm{Fe}_{\mathrm{d}}$ (valor máximo de 0,17), evidenciando o predomínio de formas mais cristalinas de óxidos de ferro, característica de solos em avançado estádio de intemperismo (KÄMPF; SCHEINOST; SCHULZE, 2000).

As razões $\mathrm{Fe}_{\mathrm{d}} / \mathrm{Fe}_{2} \mathrm{O}_{3}$ foram de 0,37, 0,27 e 0,33 para os solos de textura média, argilosa e muita argilosa, respectivamente. Os maiores valores observados para os solos de textura média e muito argilosa permitem inferir que não há relação entre a fração argila e o grau de cristalinidade dos óxidos de Fe. De acordo com Kämpf, Scheinost e Schulze (2000) a razão $\mathrm{Fe}_{\mathrm{d}} / \mathrm{Fe}_{2} \mathrm{O}_{3}$ geralmente é maior do que 0,80 nos Latossolos. Os baixos valores encontrados para esta relação no presente estudo podem ser decorrentes da alta cristalinidade dos minerais (BOUSSERRHINE et al., 1998) ou ainda de uma maior ocorrência de substituições isomórficas do $\mathrm{Fe}$ pelo $\mathrm{Al}$, diminuindo assim a velocidade de extração dos óxidos de Fe pelo DCB, conforme já demonstrado por Carvalho Junior (2000).

Os resultados da análise de componentes principais revelaram que os dois primeiros eixos explicam $64,6 \%$ da variabilidade total dos dados, sendo $51,9 \%$ e $12,7 \%$ pelo $1^{\circ}$ e $2^{\circ}$ eixos, respectivamente.

O eixo 1 foi influenciado, especialmente, pela textura do solo, onde as frações mais grosseiras (areia grossa e areia fina) apresentaram autovetores negativos, e as frações mais finas (silte e argila) apresentaram autovetores positivos. Os autovetores das frações mais finas seguem a mesma direção dos autovetores de gibbsita $(\mathrm{Gb})$, caulinita $(\mathrm{Ct})$ e $\mathrm{Fe}_{2} \mathrm{O}_{3}$ (Figura 1), confirmando a maior quantidade destes constituintes nas frações mais finas dos solos e corroborando os resultados de Marques et al. (2004) que também verificaram que os teores destes constituintes são inversamente proporcionais aos teores de areia dos solos. 


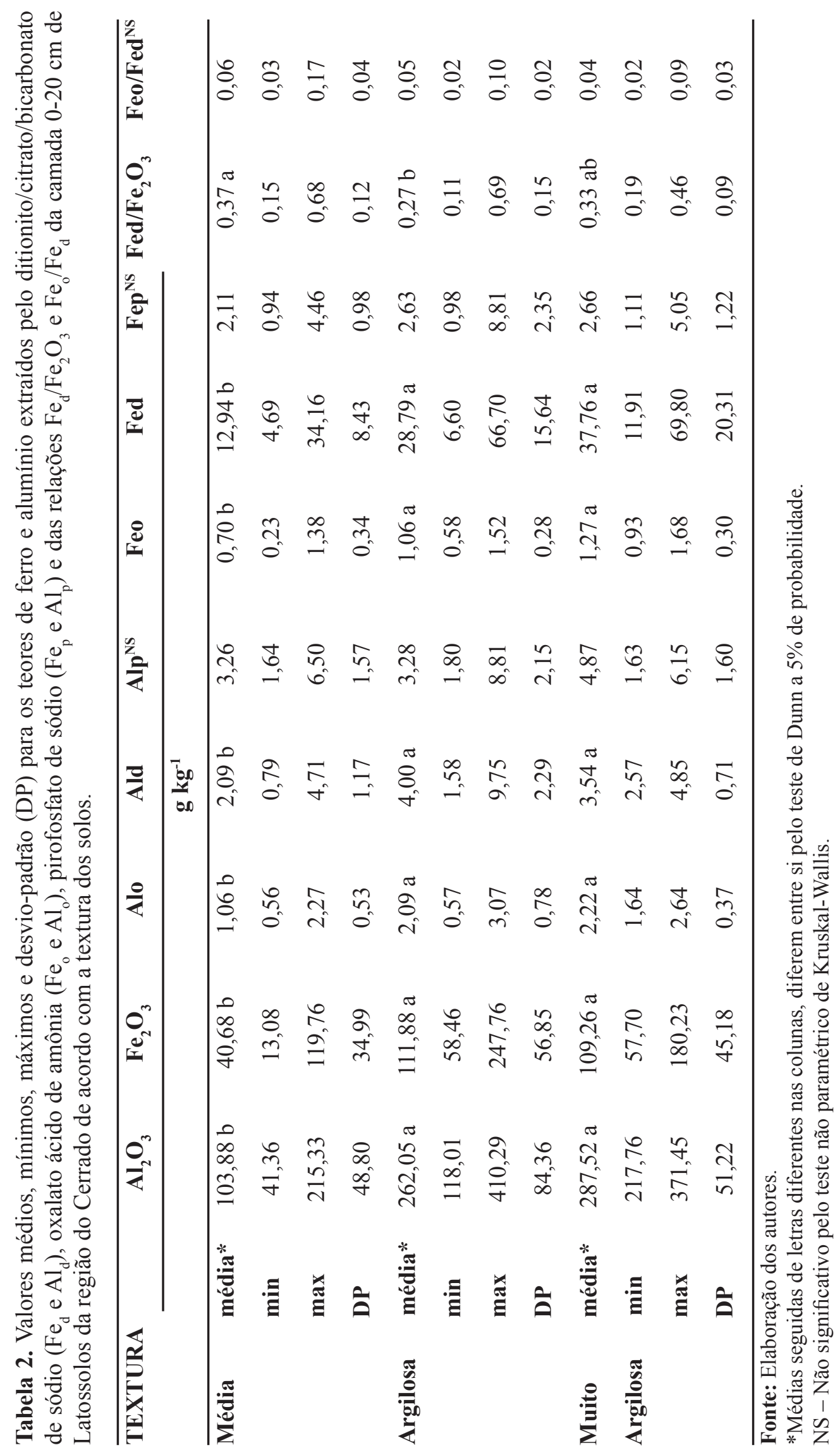


Figura 1. Círculo de correlações entre as variáveis $\mathrm{pH}_{\mathrm{H} 2 \mathrm{O}}$, Carbono orgânico (Corg), argila, silte, areia grossa, areia fina, caulinita $(\mathrm{Ct})$, gibbsita $(\mathrm{Gb}), \mathrm{Fe}_{2} \mathrm{O}_{3}, \mathrm{Al}_{2} \mathrm{O}_{3}$, ferro e alumínio extraídos pelo ditionitocitrato-bicarbonato de sódio $\left(\mathrm{Fe}_{\mathrm{d}}\right.$ e $\left.\mathrm{Al}_{\mathrm{d}}\right)$, oxalato ácido de amônia $\left(\mathrm{Fe}_{\mathrm{o}}\right.$ e $\left.\mathrm{Al}_{\mathrm{o}}\right)$ e pirofosfato de sódio $\left(\mathrm{Fe}_{\mathrm{p}} \mathrm{e}\right.$ $\mathrm{Al}_{\mathrm{p}}$ ) da camada 0-20 cm de Latossolos da região do Cerrado.

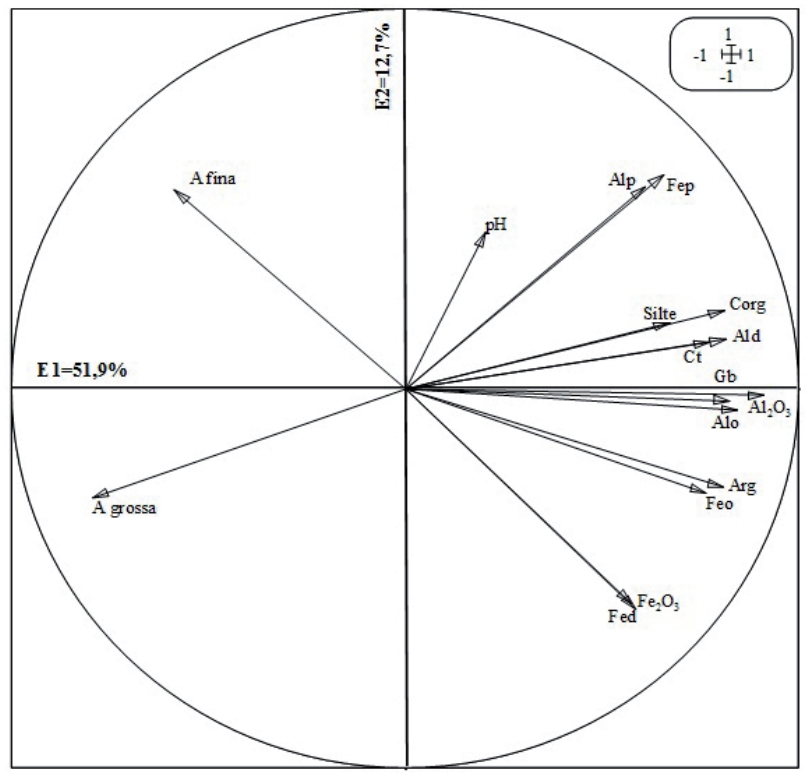

Fonte: Elaboração dos autores.

$\mathrm{O}$ eixo 2 foi influenciado pelo $\mathrm{pH}$, com autovetores positivos e, de uma forma mais limitada, pelo $\mathrm{Fe}_{2} \mathrm{O}_{3}$ e $\mathrm{Fe}_{\mathrm{d}}$ com autovetores negativos.

A maior proximidade dos autovetores dos óxidos de $\mathrm{Fe}$ de baixa cristalinidade $\left(\mathrm{Fe}_{\mathrm{o}}\right.$ e $\left.\mathrm{Fe}_{\mathrm{p}}\right)$ com o autovetor do Corg, em relação ao autovetor do Fe cristalino $\left(\mathrm{Fe}_{\mathrm{d}}\right)$, pode ser explicada pela maior superfície especifica dos óxidos de Fe de baixa cristalinidade, favorecendo a interação com a matéria orgânica do solo (CORNEJO; HERMOSÍN, 1996), como discutido anteriormente.

Os autovetores dos óxidos de Fe e de Al extraídos pelo DCB seguem a mesma direção observada para os teores totais, ou seja, com o aumento dos teores totais destes óxidos, ocorreram também aumentos das quantidades extraídas pelo DCB. Diversos trabalhos já demonstraram que a forma predominante dos óxidos de Fe no solo, influencia diretamente a quantidade de Fe extraída pelo DCB (TORRENT, 1987; FONTES, 1988), pois o ditionito é mais eficiente na extração da hematita do que na extração da goethita, devido principalmente, à maior quantidade de substituições isomórficas na goethita (FONTES; WEED, 1996).

Finalmente, observou-se que os autovetores de $\mathrm{pH}, \mathrm{Al}_{\mathrm{p}}$ e $\mathrm{Fe}_{\mathrm{p}}$ estão na mesma direção do autovetor do C-org, o que de acordo com Zech et al. (1997) se deve ao fato do aumento de $\mathrm{pH}$ no solo gerar cargas negativas na matéria orgânica, pela dissociação dos radicais carboxílicos e fenólicos. Isto pode resultar no aumento dos valores de $\mathrm{Al}_{\mathrm{p}}$ e $\mathrm{Fe}_{\mathrm{p}}$ que são as formas de óxidos de Fe e Al complexadas pela matéria orgânica dos solos.

\section{Conclusões}

Independentemente da classe textural, os óxidos de ferro de alto grau de cristalinidade representam a principal forma de ferro e se correlacionam positivamente com os teores totais de ferro do solo.

Os óxidos de alumínio apresentam maior afinidade ao carbono orgânico do solo do que os 
óxidos de ferro.

Os teores de ferro e alumínio extraídos pelo pirofosfato de sódio são estreitamente relacionados ao $\mathrm{pH}$ dos solos.

Com exceção das formas de ferro e alumínio extraídas pelo pirofosfato, todas as demais formas foram influenciadas pela textura do solo.

\section{Agradecimentos}

Ao Institut de Recherche pour le Développement, França, pelo apoio financeiro; aos laboratórios de solos da Universidade Estadual de Londrina e Embrapa Cerrados e ao laboratório de geoquímica da Université Paris-Sud 11 pelo suporte técnico.

\section{Referências}

ARIAS, M.; BARRAL, M. T.; DIAZ-FIERROS, F. Effects of associations between humic acids and iron or aluminium on the flocculation and aggregation of kaolin and quartz. European Journal of Soil Science, Amsterdam, v. 47, n. 3, p. 335-343, 1996.

AYRES, M.; AYRES JUNIOR, M.; AYRES, D. L.; SANTOS, A. A. S dos. Bio Estat. Aplicações estatísticas nas áreas das ciências médicas. 5. ed. Belém: Sociedade Civil Mamirauá, 2007. 339 p.

BOUSSERRHINE, N.; GASSER, U.; JEANROY, E.; BERTHELIN, J. Effect of aluminium substitution on ferri-reducing bacterial activity and dissolution of goethites. Comptes Rendus de l'Academie des Sciences Series IIA - Earth and Planetary Science, Paris, v. 326, n. 9, p. 617-624, 1998.

CARVALHO JUNIOR, I. A. Influência da mineralogia e da matéria orgânica na agregação, cor e radiometria de solos altamente intemperizados do Estado de Minas Gerais. 2000. Tese (Doutorado em Solos e Nutrição de Plantas) - Universidade Federal de Viçosa, Viçosa.

CLAESSEN, M. E. C. (Org.). Manual de métodos de análise de solo. $2^{\text {nd }}$ ed. Rio de Janeiro: Embrapa-CNPS, 1997. 212 p. (Embrapa CNPS. Documentos, 1).

CORNEJO, J.; HERMOSÍN, M. C. Interaction of humic substances in soil clays. In: PICCOLO, A. Humic substances in terrestrial ecosystems. Amsterdam: Elsevier, 1996. p. 595-624.

COSTA, A. C. S.; ALMEIDA, V. C.; LENZI, E.;
NOZAKI, J. Determinação de cobre, alumínio e ferro em solos derivados do basalto através de extrações seqüenciais. Química Nova, São Paulo, v. 25, n. 4, p. 548-552, 2002.

EBERHARDT,D.N.;VENDRAME, P. R. S.;BECQUER, T.; GUIMARÃES, M. F. Influência da granulometria e da mineralogia sobre a retenção de fósforo em Latossolos sob pastagens no Cerrado. Revista Brasileira de Ciência do Solo, Viçosa, MG, v. 32, n. 3, p. 1009-1016, 2008.

FONTES, M. P. F. Iron oxide mineralogy in some brazilian oxisols. 1988. PhD thesis (Soil Science) - North Carolina State University, Raleigh.

FONTES, M. P. F.; WEED, S. B. Phosphate adsorption by clays from Brazilian Oxisols: relationships with specific surface area and mineralogy. Geoderma, Amsterdam, v. 72, n. 1-2, p. 37-51, 1996.

GENÚL, A. M.; DEMATTÊ, J. A. M.; FIORIO, P. R. Análise espectral de solos da Região de Mogi-Guaçú (SP). Semina: Ciências Agrárias, Londrina, v. 31, p. 1235-1244, 2010. suplemento 1.

GHIDIN, A. A.; MELO, V. F.; LIMA, V. C.; LIMA, J. M. C. Topossequências de Latossolos originados de rochas basálticas no Paraná. I - mineralogia da fração argila. Revista Brasileira de Ciência do Solo, Viçosa, MG, v. 30, n. 2, p. 292-306, 2006.

GOMES, J. B. V.; CURI, N.; MOTTA, P. E. F.; KER, J. C.; MARQUES, J. J. G. S. M.; SCHULZE, D. G. Análise de componetes principais de atributos físicos, químicos e mineralógicos de solos do bioma cerrado. Revista Brasileira de Ciência do Solo, Viçosa, MG, v. 28, n. 1, p. 137-153, 2004.

INDA JUNIOR, A. V.; KÄMPF, N. Avaliação de procedimentos de extração dos óxidos de ferro pedogênicos com ditionitocitrato-bicarbonato de sódio. Revista Brasileira de Ciência do Solo, Viçosa, MG, v. 27, n. 6, p. 1139-1147, 2003.

KÄMPF, N.; SCHEINOST, A. C.; SCHULZE, D. G. Oxide minerals. In: SUMNER, M. E. (Ed.). Handbook of soil science. University of Georgia, Athens, GA, USA: CRC Press, 2000. p. 125-168.

LILIENFEIN, J.; WILCKE, W.; VILELA L.; AYARZA M. A.; LIMA S. C.; ZECH W. Soil Fertility under Native Cerrado and Pasture in the Brazilian Savanna. Soil Sci. Soc. Am. J. Madison, Wisconsin, USA, v. 67, p. 11951205, 2003.

LINDSAY, W. L; NORVELL, W. A. Development of a DTPA soil test for zinc, iron, manganese and copper. Soil Science Society of America Journal, Madison, v. 42, n. 2, p. 421-428, 1978. 
MARQUES, J. J.; SCHULZE, D. G.; CURI, N.; MERTZMAN, S. A. Major element geochemistry and geomorphic relationships in Brazilian Cerrado soils. Geoderma, Amsterdam, v. 119, n. 3-4, p. 179-195, 2004.

MEHRA, O. P.; JACKSON, M. L. Iron oxide removal from soils and clays by a dithionite-citrate system buffered with sodium bicarbonate. In: NATIONAL CONFERENCE ON CLAYS AND CLAYS MINERALS, 7., 1960, Washington, D.C. Proceedings... New York: Pergamon Press, 1960. p. 3 17-327.

MELO, V. F.; SINGH, B.; SCHAEFER, C. E. G. R.; NOVAIS, R. F.; FONTES, M. P. F. Chemical and mineralogical properties of kaolinite-rich Brazilian soils. Soil Science Society of America Journal, Madison, v. 65, n. 4, p. 1324-1333, 2001.

OLIVEIRA, A. B.; NASCIMENTO, C. W. A. Formas de manganês e ferro em solos de referência de Pernambuco. Revista Brasileira de Ciência do Solo, Viçosa, MG, v. 30, n. 1, p. 99-110, 2006.

PARFITT, R. L.; CHILDS, C. W. Estimation of forms of Fe and Al: a review, and analysis of contrasting soils by dissolution and Moessbauer methods. Australian Journal of Soil Research, Victoria, v. 26, n. 1, p. 121-144, 1988.

PEDROTTI, A.; FERREIRA, M. M.; CURI, N.; SILVA, M. L. N.; LIMA, J. M.;CARVALHO, R. Relações entre atributos físicos, mineralogia da fração argila e formas de alumínio no solo. Revista Brasileira de Ciência do Solo, Viçosa, MG, v. 27, n. 1, p. 1-9, 2003.

REATTO, A.; BRUAND, A.; MARTINS E. S.; MULLER F.; SILVA, E. M.; CARVALHO JUNIOR, O. A. Variation of the kaolinite and gibbsite content at regional and local scale in Latosols of the Brazilian Central Plateau. Comptes Rendus de Geoscience, Paris, v. 340, n. 11, p. 741-748, 2008.

SANTOS, H. G. dos; JACOMINE, P. K. T.; ANJOS, L. H. C. dos; OLIVEIRA, V. A. de; OLIVEIRA, J. B. de; COELHO, M. R.; LUMBRERAS, J. F.; CUNHA, T. J. F. (Ed.). Sistema brasileiro de classificação de solos. $2^{\text {nd }}$ ed. Rio de Janeiro: Embrapa Solos, 2006. 306 p.

SUN, Y. C.; CHI, P. H.; SHIUE, M. Y. Comparison of different digestion methods for total decomposition of siliceous and organic environmental samples. Analytical Sciences, Tokyo, v. 17, n. 12, p. 1395-1399, 2001.

THIOULOUSE, J.; CHESSEL, D.; DOL'EDEC, S.; OLIVIER, J. M. ADE-4: a multivariate analysis and graphical display software. Statistics and Computing, Paris, v. 7, n. 1, p. 75-83, 1997.

TORRENT, J. The reductive dissolution of synthetic goethite and hematite in dithionite. Clay Minerals, Cordoba, v. 22, n. 3, p. 329-337, 1987.
VENDRAME, P. R. S.; BRITO, O. R.; GUIMARÃES, M. F.; MARTINS, E. S.; BECQUER, T. Caracterização da solução de solos do Bioma Cerrado sob pastagens. Semina: Ciências Agrárias, Londrina, v. 28, n. 2, p. 167$178,2007$.

WANG, C. Extractable Al, Fe and Mn (and Si if desired). In: McKEAGUE, J. A. (Ed.). Manual on soil sampling and methods of analysis. 2. ed. Otawwa: Canadian Society of Soil Science, 1978. p. 98-108.

ZECH, W.; SENESI, N.; GUGGENBERGER, G.; KAISER, K.; LEHMANN, J.; MIANO, T. M.; MILTNER, A.; SCHROTH, G. Factors controlling humification and mineralization of soil organic matter in the tropics. Geoderma, Amsterdam, v. 79, n. 1-4, p. 117-161, 1997. 
